\title{
Feasibility of PV Integrated Microgrids in Remote North Canadian Communities
}

\author{
Tim Yusishen, Amin Hajihosseinlu, Mathias Pielahn, Iman Kaffashan, Azita Fazelkhah, and \\ Dharshana Muthumuni
}

\begin{abstract}
In this paper a methodology for a transition away from a fossil fuel dependency to clean energy in remote communities in northern Canada is presented. Both technical and non-technical obstacles associated with such a transition to clean energy are outlined. A proposal on how to possibly overcome these obstacles is also presented. The technical aspect of this work includes a case study on one of the communities in northern Manitoba, Canada. The case study is supported by simulations, using the software tool PSCAD ${ }^{\mathrm{TM}} / \mathrm{EMTDC}^{\mathrm{TM}}$. The simulation result illustrates how the control system coordinates various parts of a microgrid and reduces annual diesel consumption.
\end{abstract}

Index Terms-Microgrid, clean energy, remote community, renewable energy.

\section{INTRODUCTION}

$\mathrm{T}$ he Aboriginal Affairs and Northern Development of Canada (AANDC) defines an off-grid community or long-term settlement as one that is not connected to the North American electric grid. In short, for this paper, such communities or settlements are called remote communities. Of Canada's 292 remote communities, 257 are electrified by diesel generators [1]. Reliable, cost-effective, and efficient energy supply for these remote communities is a challenge gaining major attention from federal and provincial leaders. Access to these communities is difficult due to their remote locations. Studies show that there are systematic barriers such as public policy, technical solutions, and capacity for change to implement a clean energy system [1].

Diesel is the standard fuel for electricity generation in most of Canada's remote communities [2]. Providing energy for remote communities using diesel fuel is accompanied by environmental, financial and social challenges. These include greenhouse gas (GHG) emissions and localized air pollution, adverse health impacts of diesel contamination for communities' residents and high and fluctuating cost of fuel.

The fluctuating costs of fuel is especially pronounced as transporting fuel to remote communities is expensive due to their remote locations, some of which are only accessible by winter roads or planes [3].

Manuscript received October 18, 2019; revised October 30, 2019, accepted November 8, 2019.

Tim Yusishen, Amin Hajihosseinlu, Iman Kaffashan, and Azita Fazelkhah are with Solar Engineers Int., Inc. Winnipeg, MB, Canada (email: tim@solarengineers.com, \{hajihosseinlu, imankaffashan, a.fazelkhah @ gmail.com)

Mathias Pielahn is with Pylon Technology Solutions Ltd. (e-mail: Mathias.Pielahn@PTSolns.com).

Dharshana Muthumuni is with Manitoba Hydro International Ltd., Winnipeg, Manitoba, Canada, (e-mail: dharshana@mhi.ca).
Due to these reasons, integrating reliable renewable solutions into these remote communities, via microgrids, is of high priority.

For the purpose of this paper, a microgrid is defined as an interconnected set of loads and energy generation sources that can function autonomously in the absence of an integrated national electrical grid. Microgrids and related technologies comprise a rapidly-expanding market, which in 2015 was estimated at US\$7 billion with an installed capacity of $1.2 \mathrm{GW}$ [3].

The 2016 Canadian government budget allocated an investment of $\$ 4.5$ billion over five years to support infrastructure development in indigenous communities [4]. To date, $\$ 640$ million has been allocated to support the deployment of renewable energy (RE) projects to reduce diesel consumption [5]. However, there are several systemic barriers inhibiting microgrid solutions from being deployed across Canada.

There is a lack of industry experience in integrating RE technologies into off-grid, remote communities. Furthermore, the details of the total cost of renewable solutions and the associated technology reliability risk are not well understood. Complicated diesel procurement funding streams that cause complexity in incentive structure for clean energy implementation, lack of viable contracting methods for generation of clean energy and no mechanism to place incentives as a result of environmental and socio-economic benefits are some of the public policies barriers regarding clean energy system implementation.

There have been reports on projects investigating RE alternatives such as wind turbine and photovoltaic in dieselbased microgrid remote communities in northern Ontario. Three projects in Ontario integrating wind turbine with diesel-based microgrids, Photovoltaic (PV) systems in the Northwest Territories and Nunavut are some of the examples of diesel-based microgrids in remote communities in Canada [6]. These projects had a mixture of planning, operation, and maintenance issues that limited their lifetime to only a few years.

In this work, the authors propose a possible solution intended to overcome the current systematic barriers by implementing clean energy while reducing the cost, dependence, and environmental effects of traditional diesel generators. The paper is organized as follows: Section II discusses the impacts of diesel consumption and clean energy development, potential, and challenges. Section III presents the case study developed in collaboration with Tadoule Lake and discusses the simulation results and a feasibility study on a photovoltaic (PV) farm in this location using the EMT simulation tool $\mathrm{PSCAD}^{\mathrm{TM}} / \mathrm{EMTDC}^{\mathrm{TM}}$. Finally, Section IV highlights the main conclusions and contributions. 


\section{CleAN ENERGy DEVElopMENT, Potential AND CHALLENGES}

Fossil fuels such as coal, oil and natural gas, are the dominant energy sources globally, as presented in Fig. 1. However, over the last few decades, a transition from fossil fuels toward renewable energy sources (RES), namely biomass, hydropower, geothermal, solar and wind, has increased in popularity.

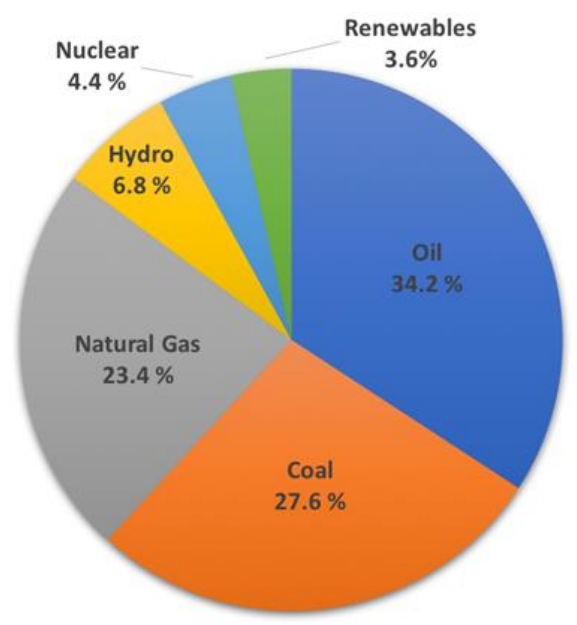

Figure 1. Global energy consumption by source, 2017 [7]

This transition is motivated by concerns about environmental impacts on climate change, dependence on fossil fuel and the associated varying costs. Throughout the past 15 years, the global market for RE technologies has experienced strong growth as illustrated in Fig. 2. Initially, government subsidies have allowed for increased RE penetration into a competitive market, dominated by fossil fuel-based energy generation.

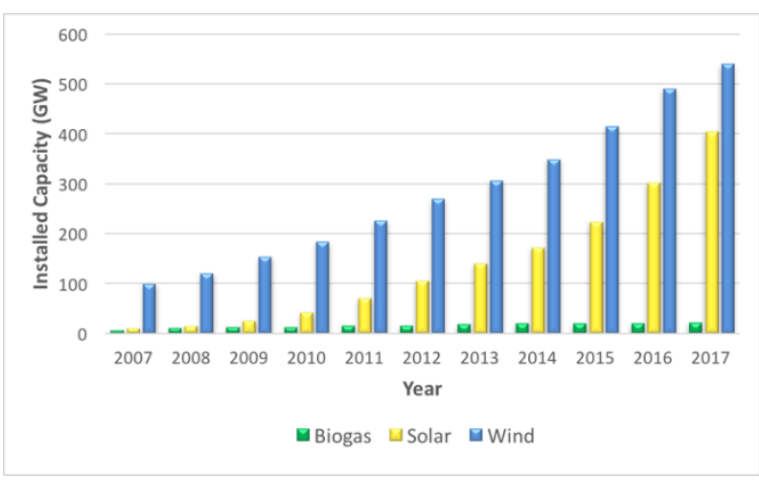

Fig. 2. Global installed capacity of wind power, Photovoltaic, and Biogas, 2007-2017 [8]

With the technology advancing, the overall cost of commissioning RES has continued to decrease. The current trend is that in many projects even without government subsidies, RE technologies are competitive compared to conventional fossil-fuel-based energy sources. Considering recent technological developments concerning microgrids, RE technologies (including wind and solar PV) and energy storage, renewable-diesel hybrid systems could help strengthen energy supply security at off-grid sites.

The daily supply of solar energy is theoretically sufficient to meet all human energy needs for an entire year [9]. However, solar energy and other RES are limited in that their availability varies across space and time. For instance, generating electricity from $100 \%$ solar is not always feasible in the sense of the space requirements. Thus, a hybrid of sources is the ultimate solution.

Recently, the concept of microgrids is gaining attention as a promising energy option. Microgrids can be categorized according to various criteria, from production type to size to the type of application that they serve. As illustrated in Figure 3 , a microgrid predominately consists of energy production sources such as wind, solar and diesel, electrical loads, energy storage systems, and control/protection mechanism. Microgrids represent an interesting market in terms of energy production and are expected to grow in the next few years.

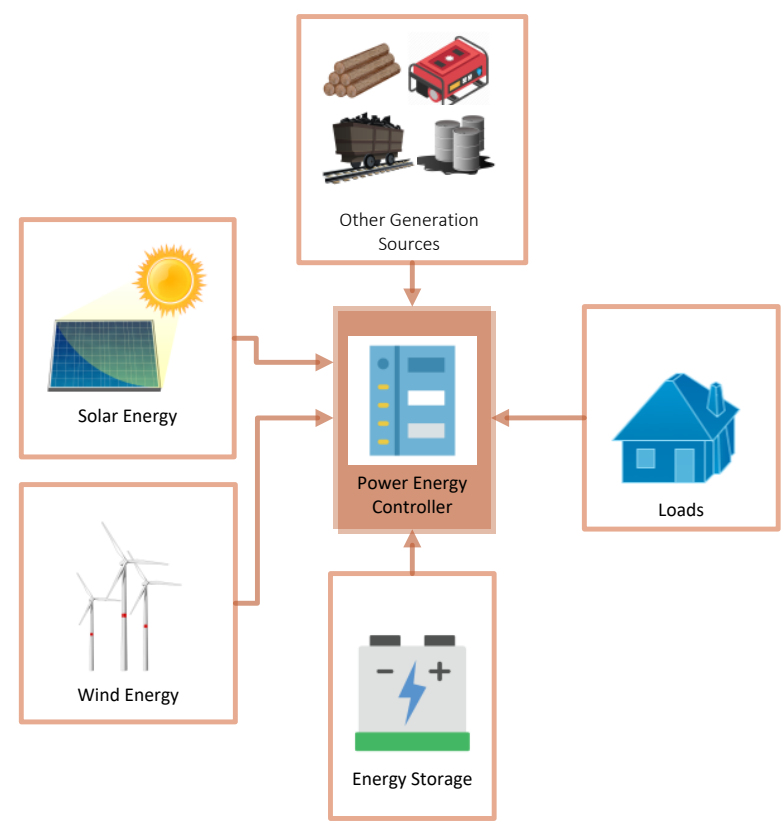

Fig. 3. Microgrid configuration

Electricity rates in remote communities are significantly higher compared to large population centers. Electricity rates for communities with all-year-round road access is as low as CAD $\$ 0.45 / \mathrm{kWh}$, while a location that is mainly accessible by barge or plane can scale to $\mathrm{CAD} \$ 0.80 / \mathrm{kWh}$. For arctic locations, the rate varies from CAD $\$ 1.50 / \mathrm{kWh}$ to CAD $\$ 2.50 / \mathrm{kWh}$. For a hydro-based generation, the rates in northern remote communities range from CAD $\$ 0.15 / \mathrm{kWh}$ to CAD $\$ 0.40 / \mathrm{kWh}$, depending on the community's location and installed capacity. In contrast, in the rest of Canada, depending on the province, average electricity rates vary from CAD $\$ 0.07 / \mathrm{kWh}$ to CAD\$0.17/kWh [10]. This situation of extreme differences in electricity rates often forces governments to subsidize energy supplies to ensure that they remain accessible. In this context, microgrids that combine wind and solar PV represent an excellent opportunity to diversify and secure energy supply in stand-alone fossil-fuelbased microgrids, while reducing the use of fossil fuels such as diesel. Harnessing energy sources that are renewable, clean and locally available is a competitive alternative to importing fossil fuels such as diesel. However, integrating RE into stand-alone microgrids comes with its share of technical, economic and social challenges.

\section{A. Economic challenges}

Approximately $80 \%$ of the world's energy supply is provided by traditional fossil fuels, in part due to the low costs of mining/drilling/etc such fuel and the fact that the associated technology is mature [9]. However, the cost advantage of 
fossil fuels over RES has been decreasing in recent years, and specific RES can already compete with fossil fuels financially without any government subsidies. Based on the US Energy Information Administration (EIA) projects, fossil fuel prices will steadily continue to rise until 2040. The predicted price hike is $76 \%$. Furthermore, according to supply and demand, prices will continue to fluctuate over time. Therefore, even without promoting a transition toward RES, economic factors are currently moving toward that direction.

Calculation of the levelized cost of energy (LCOE) enables the cost comparisons between different energy sources. Levelized costs represent the present value of the building and operating a plant over an assumed lifetime, expressed in real terms to remove the effect of inflation. For energy sources that require fuel, assumptions are made about future fuel costs. In order to compare different energy sources directly, the levelized construction and operations costs are divided by the total energy obtained. Most RES requires large capital investments compared to fossil fuels, as shown in Table I.

TABLE I. THE CAPITAL COST OF ELECTRICITY SOURCES [9]

\begin{tabular}{lcccc}
\hline & $\begin{array}{c}\text { Nominal } \\
\text { Capacity } \\
\text { (MW) }\end{array}$ & $\begin{array}{c}\text { Capital Cost } \\
\text { (CAD\$/kW) }\end{array}$ & $\begin{array}{c}\text { Capacity } \\
\text { Factor } \\
(\%)\end{array}$ & $\begin{array}{c}\text { Capital } \\
\text { CAD\$/ } \\
\text { Expected } \\
\text { kW }\end{array}$ \\
\hline Natural gas & 620 & 1,200 & 90 & 1,019 \\
Coal & 650 & 4,246 & 90 & 3,607 \\
Hydroelectric & 500 & 3,841 & 75 & 3,915 \\
Wind & 400 & 8,149 & 35 & 17,800 \\
Solar & 150 & 5,066 & 20 & 19,365 \\
\hline
\end{tabular}

Renewable solar and wind energy sources come with high capital expenditure compared to fossil fuels however there is an advantage over fossil fuels which is lower operating costs once facilities are built. For comparing sources with different capacity factors, CAD\$/expected $\mathrm{kW}$ is defined as $(\mathrm{CAD} \$ / \mathrm{kW}) /($ capacity factor), or the capital cost to produce the same amount of electricity as one $\mathrm{kW}$ of capacity running continuously. The above discussion assumes there is no regulated free market for energy, which is not the case today as there are many financial supports and subsidies such as direct payments or favorable loans, tax credits and deductions, and price supports by government.

According to an analysis by Bloomberg New Energy Finance, allocated support for fossil fuels are twelve times more than the ones toward RE. Many countries are increasing their supports toward RE. There are examples of global subsidies for RE. As an example, global subsidies for RE were CAD $\$ 56$ to CAD $\$ 60$ billion, mainly in the form of tax credits and feed-in tariffs in 2009. Germany had one of the most expensive RE subsidy in 2009, equivalent to CAD $\$ 13$ billion. Other feed-in tariffs in Europe totaled another CAD $\$ 13$ billion. The United States spent more than any other country on RE subsidies, around $\$ 18$ billion. The Ontario Power Authority (OPA) launched the FIT program to procure $\mathrm{RE}$ technologies with small scale solar PVs receiving the highest tariff rate of $80.2 \mathrm{CAD} \$ / \mathrm{kWh}$ for rooftop solar PV in 2009 [11].

\section{B. Social challenges}

There have been a number of microgrid projects integrating renewables at off-grid sites across Canada. However, several of these projects were not as successful as had been hoped due to the previously mentioned difficulties. The issue of social acceptability might be raised for such projects for which a certain social resistance emerges despite the endorsement of governments and environmental groups. In order to overcome this challenge, more examples and data from successfully deployed systems is needed, to instill confidence and strengthen business cases for future projects. There is an example of a successful project in the Caribbean where a Diesel-free power system in two expansion stages was deployed. The total solar power output and battery capacity reached $4.15 \mathrm{MW}$ and $5,900 \mathrm{kWh}$, respectively [12]. This system helped to reduce the consumption of the diesel generators by as much as 1.8 million liters of fuel annually. Another example of a successful project is Nemiah valley photovoltaic-Diesel mini-grid in British Colombia in 2007.

In some cases, lack of strong communication, and insufficient levels of decision-making authority afforded to community leaders, resulted in slowing down or even stopping of such projects. Many felt that some past projects have lacked meaningful collaboration with residents, or have not included the community in important decision-making processes. A lack of knowledge and technical proficiency within the communities was a significant obstacle to developing these collaboration models, compounded by a lack of training opportunities available to acquire the skills and knowledge needed within the community. Training the local consumers and increasing their engagement in the projects is another solution to increase the capacity for change among communities. For instance, in 2018 a fully integrated microgrid at Kiashke Zaaging Anishinaabek (KZA) community was implemented and tested successfully. One of the objectives of this project in engaging locals is educating youth about renewable energies. Through KZA's ownership of the microgrid, thousands of liters of diesel fuel will be replaced with clean solar power.

\section{Technical challenges}

Incorporating RE into remote off-grid systems presents various technical challenges. Participants believe that there is a lack of understanding of the technical feasibility of implementing renewables into remote communities. Adapting the various energy systems and developing robust control systems is indispensable to facilitate renewables integration into microgrids and to absorb the rapid frequency fluctuations generated by renewable sources. An issue of frequency fluctuation may arise in order to achieve a possible collapse of the network. Due to the fluctuating behavior of RES, balancing, generation and demand are not simple tasks for the main control system unit since the power from the RES is not constant. Therefore, this phenomenon leads to control the variables in order to maintain an acceptable level of frequency in the power network by increasing the penetration of RES.

Furthermore, it is necessary to ensure the stability of a microgrid and allow for high renewable penetration levels. In other words, the major challenge of a hybrid RE microgrid is the penetration rate of RES. The renewable energy penetration rate is defined as power produced from RE concerning the power consumed at any given moment. The maximum penetration rate of RES is limited according to the fact that providing load by RES will lead diesel generator (DG) to become irreversibly damaged due to the adverse effects of low load operation on DG. By adding storage and an advanced microgrid control system, this rate can practically increase. However, current storage technologies continue to have relatively low energy storing capacities and very high costs. The reliability and availability of the storage 
system are substantially important, particularly in extremely cold weather, which is typical for remote communities in Canada. Vast research remains to be conducted in the field of energy storage and its adaptation to cold climates.

Another technical challenge related to the integration of $\mathrm{RE}$ is power quality influenced by voltage and frequency fluctuations. These fluctuations are caused by noncontrollable variability of RES and harmonics, which are introduced by power electronic converters used in RE generation [6].

An Energy Management System would be required to efficiently control the different power generators [13], [14]. There is also the need for dump loads to handle excess RE, and thus avoid frequency stability issues. In addition, in high RE-penetration levels, diesel plants could potentially be turned off for certain period. Hence, in cold climates, a diesel plant heating system is required to assure that the engines can start-up again quickly [15].

Diesel generators in remote northern locations are usually oversized due to the large difference between average and peak load, and as a result, generators usually run at partial load resulting in significantly lower efficiency rates; most remote northern communities have installed different rated generator capacities to partially overcome low-load issues [13], [15]. Moreover, the generator's efficiency is likely to be further reduced when RE equipment is integrated into the microgrid due to the negative load that RE generation implies. RE integration would likely keep diesel generators running longer at partial load conditions, which will result in carbon build up in cylinder heads and pistons, that can be potentially overcome by succeeding periods of full-load runtime [16], [17].

In order to address some of the challenges for integration of RES into the standalone microgrids, a technical examination, and feasibility study are presented in section IV to ensure that adding the RES along with energy storage will not affect the power quality and reliability of the remote communities.

\section{CASE STUdY: SySTEM AND DATA}

In this work, Tadoule Lake in northwestern Manitoba is presented as a case study. The registered population of the community as of August 2011, was 330 members [18]. In this region, the annual average temperature falls below $-6^{\circ} \mathrm{C}$. This community is accessible using plane, snowmobile, dog sleds, and in winter by winter road. As the winter roads operate only for one or two months per season, most of the supplies for the entire year is transported and stored during this period in winter. Transportation of diesel is mostly done over winter roads, which are costly and hazardous to both people and the environment. Moreover, diesel storage facilities deployed in these settlements are susceptible to fuel tank leaks that can cause significant environmental. The highest impact to the environment is caused by the burning of a large amount of diesel, contributing significantly to greenhouse gas emissions.

\section{A. System Configuration}

The PV array used in the case study consists of monocrystalline silicon cells (LG390N2T-A5), each rated at $390 \mathrm{~W}$, with the $18.5 \%$ efficiency. The case has a fixed photovoltaic system configuration so that each module is tilted with a slope of $45^{\circ}$ (south).

\section{B. Load Profile}

Based on the provided data by Manitoba Hydro, the provincial utility that provides electricity and gas service to communities throughout the province, the annual demand and average load of this community are about 2400MWh and 308 $\mathrm{kW}$, respectively. The voltage at load side is assumed to be 208 V. A hybrid system combining PV, battery storage and a diesel generator is proposed for the isolated system initially designed with five diesel generators and maintained by Manitoba Hydro.

As mentioned in section II, the battery storage system is required to increase the RE penetration rate. If only $\mathrm{PV}$ is added to a weak grid, the DG must respond to more fluctuating load demand. Furthermore, there are major technical difficulties to keep the grid reliable in such fluctuations in the load profile. There are also some fluctuations in generated power on a cloudy day. Therefore, the swings in the load profile and/or generated power by the PV could be filtered by adding the batteries constantly charging to use excessive power or discharging to compensate for the shortage of power. In other words, batteries will see a constantly changing power; however, the DGs work at their optimal operating points.

Based on the monthly consumption of Tadoule Lake community, a 1.29 MW PV system along with a 1.2MWh battery storage is proposed. Fig. 4 shows the monthly production and consumption of the Tadoule lake community. The renewable energy fraction for this system is about $67 \%$, which means $67 \%$ of the annual power consumption is generated by clean energy from the sun and the other $33 \%$ comes from the diesel generator. This system saves about 510540 liters of diesel per year. From this, the saving from the cost of only diesel would be more than $\$ 510540$ per year assuming diesel cost \$1/litre.

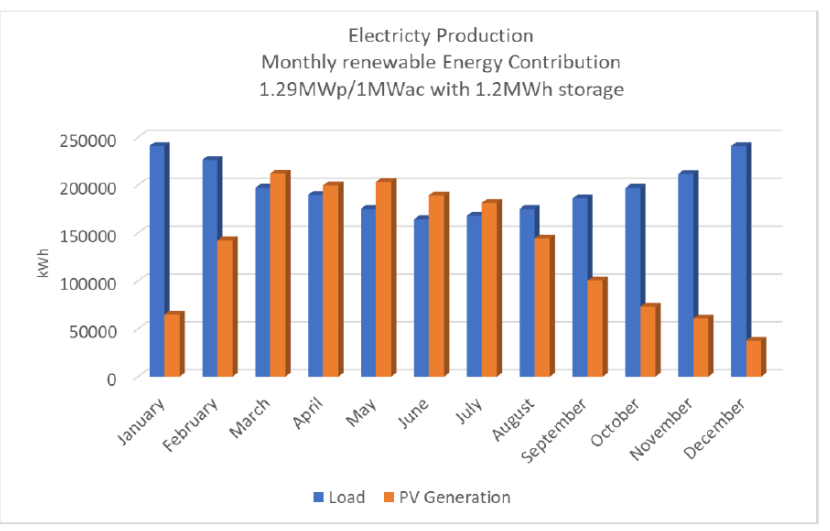

Fig. 4. Electricity production by the PV- Battery system vs the monthly community load

In addition to the cost of fuel, there are more savings from the transportation of the fuel, cost of storage of the fuel, the cost associated with the environmental remediation caused by diesel spills, and more importantly reduction in the cost of operation and maintenance of the diesel generators. Since this case study is scalable, by adding more PV modules and more battery storage, DGs could be shut down, and acting only as a backup during weeks of a snowstorm.

\section{Financial Viability Study}

In this work, the financial viability of the Tadoule lake case study was assessed using the RETScreen software developed 
by the Government of Canada [19]. The analysis has been performed by using the RETScreen Clean Energy Project Analysis software, which is able to perform energy production analysis, financial analysis, and GHG emission analysis. RETScreen software takes into account details such as the energy resource available at project site, equipment performance, initial project costs, on-going and periodic project costs, avoided cost of energy, financing, environmental characteristics of energy displaced, environmental credits and/or subsidies and decision maker's definition of cost-effective [19], [20]. One of the primary advantageous of using RETScreen software is that it simplifies the decision-making process for the investors. The financial analysis worksheet contains financial parameters input items (e.g. discount rate, inflation rate, debt ratio, etc.), and its calculated financial viability output items (e.g. internal rate of return (IRR), simple payback, net present value (NPV), etc.). In this case study, these parameters are defined as follows and reported in Table II.

TABLE II. RETSCREEN PARAMETERS

\begin{tabular}{lc}
\hline Daily solar radiation- & $3.06 \mathrm{kWh} / \mathrm{m} 2$ day \\
horizontal & $4.2 \mathrm{kWh} / \mathrm{m} 2$ day \\
Daily solar radiation- tilted & $1548.34 \mathrm{MWh}$ \\
Annual Electricity & $2379 \mathrm{MWh}$ \\
Electricity delivered to load & $\$ 18000000$ \\
Total initial cost & $\$ 500000$ \\
Annual cost (O\&M) & $25 \$ / \mathrm{CO} 2$ \\
Carbon tax & $6 \%$ \\
Discount rate & $1 \%$ \\
Fuel cost escalation rate & $2 \%$ \\
Inflation rate & 20 years \\
Project life & \\
\hline
\end{tabular}

The project lifetime is set to 20 years, which is typical for renewable energy projects. The inflation and discount rates are 2 and 6 percent, respectively. A carbon tax of $25 \$ / \mathrm{tCO} 2$ was imposed on the $\mathrm{CO}_{2}$ emissions to find $\mathrm{GHG}$ reduction through this project [21].

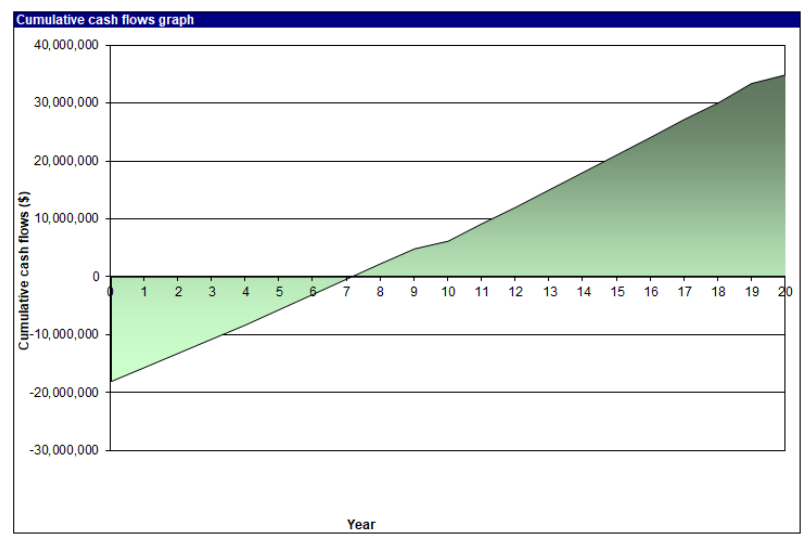

Fig. 5. Cumulative cash flow over 20 years in Tadoule Lake

The electricity export rate is $0.3 \$ / \mathrm{kWh}$. Annual O\&M cost and 10 -year costs are $\$ 500 \mathrm{k}$ and $\$ 1500 \mathrm{k}$, respectively. Based on the results from RETScreen, the annual GHG reduction is 139 tCO2.

\section{TECHNICAL FEASIBILITY AND EXAMINATION}

A. Simulation of the Microgrid using $P S C A D^{T M} / E M T D C^{T M}$ The Tadoule Lake's simulation case including the power grid, the renewable energy system, and microgrid controller is modeled using the EMT simulation software tool PSCAD. Figure 6 shows a diagram of the studied microgrid system. The technical feasibility of the proposed model and control system for managing the interaction between all components within the microgrid is investigated. In addition, this simulation case could be used to perform a thorough interconnection study of the PV and storage system.

For installation of renewable energy sources to an existing diesel-based microgrid, it is required to demonstrate that adding renewable energy sources along with energy storage will not affect the power quality and reliability of these indigenous communities. During the following tests, all the voltages, current, frequency, and total harmonic distortion (THD) must remain in an acceptable range and complies with IEEE standards, as well as local grid requirements.

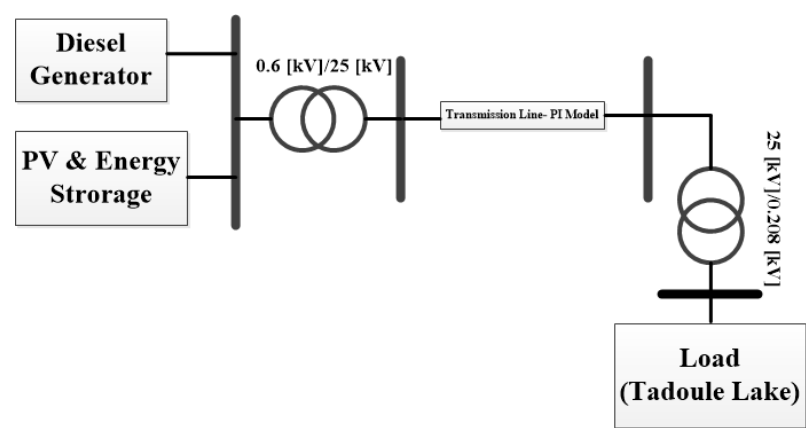

Figure 6. Proposed microgrid system.

Figure 7 shows a flowchart that illustrates the interconnection test bench of the simulation case that includes all the possible scenarios for the proposed hybrid microgrid model.

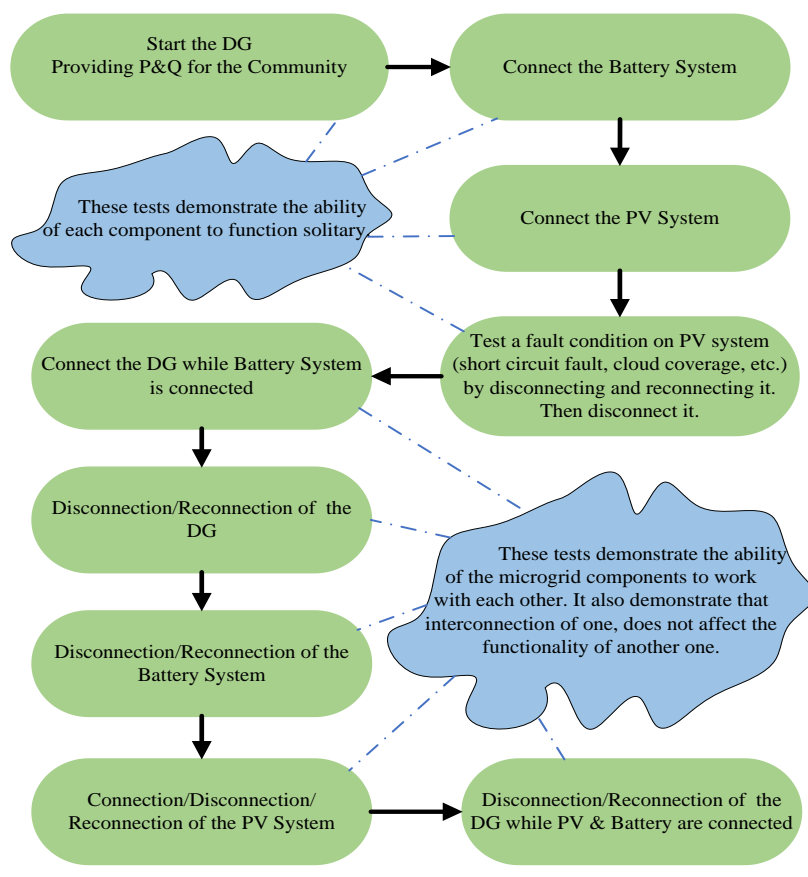

Fig. 7. Flowchart of the simulation case test sequence.

Tests could be divided into two groups. These groups consist of tests for demonstrating the ability of each component to function solitary and with each other during normal or fault situation. In the second group, it is required to test the interconnection of one does not affect the functionality of another one. The tests within both groups are explained as follows. 
Two scenarios are presented in this paper. These simulations are performed in PSCAD and are meant to give a general idea of the equipment and system's behavior. The transients resulting from switching and system events are strongly influenced by the controls of the system as well as the characteristics of the equipment itself. The scenarios outlined in this paper show general responses to non-specific controls.

\section{Scenario 1}

This case shows the system's response when the load is initially powered by the diesel generator and the PV and battery are added, successively. In this case the diesel is on initially, while the PV and battery are off. At $\mathrm{t}=5 \mathrm{sec}$ the PV is turned on, with irradiation at $100 \%(1200 \mathrm{~W} / \mathrm{m} 2)$. At $\mathrm{t}=10$ seconds the battery is turned ON. This is shown in Fig. 8. The voltage THD for the phases $\mathrm{a}, \mathrm{b}$ and $\mathrm{c}$ at the load are monitored, and remain below $3 \%$ while in steady state.

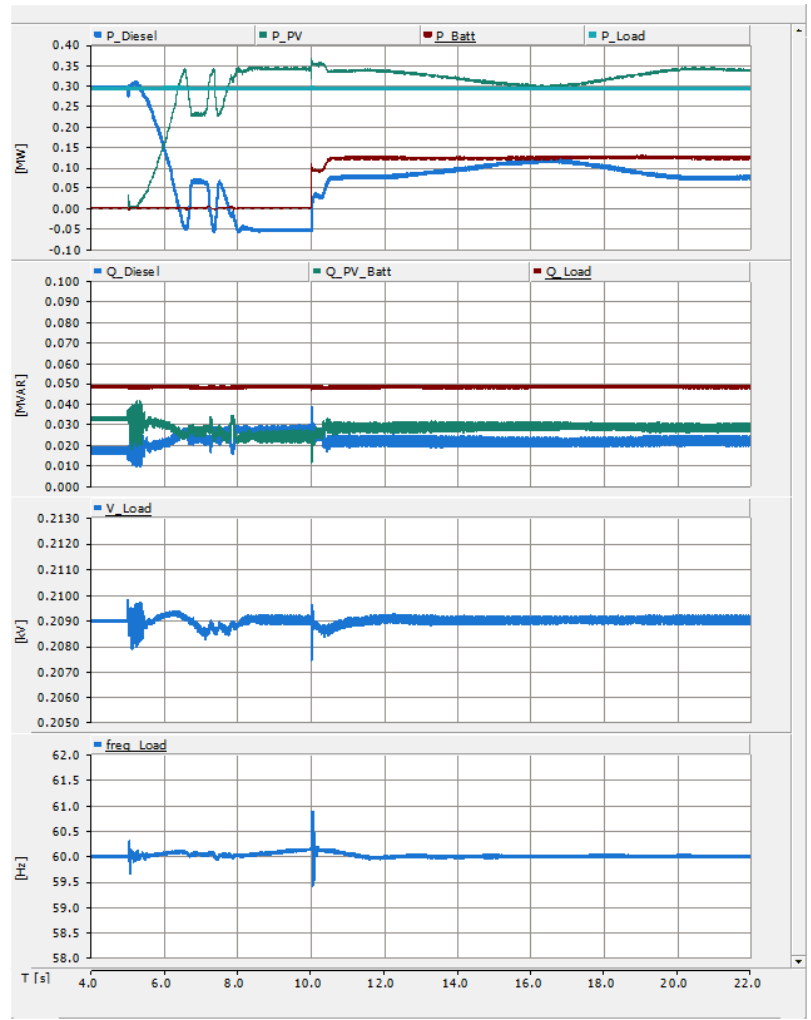

Fig. 8. Scenario 1, Real power $(\mathrm{P})$, reactive power $(\mathrm{Q})$, voltage $(\mathrm{V})$, and frequency (f).

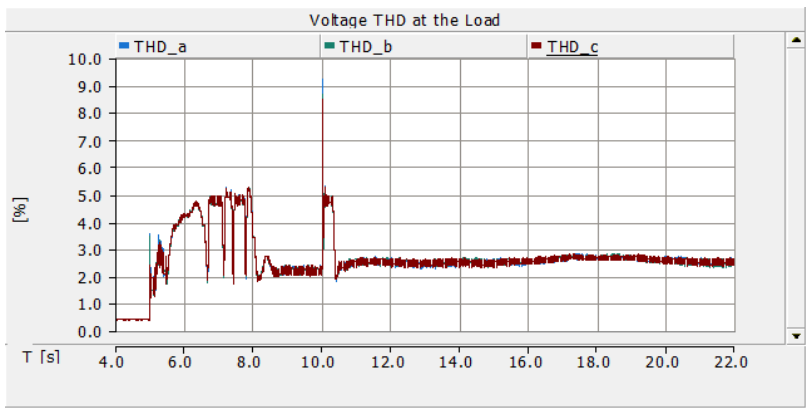

Fig. 9. Scenario 1, Total Harmonic Distortion (THD).

The THD shortly peaks to $10 \%$ when the battery is switched on at $t=10$ seconds. This is shown in Fig. 9. Note that the battery is charging. The convention used is that positive power is going into the battery is charging. It can be seen that after a short transient caused by turning on the PV and battery, the system settles to a different operating condition. The transient can be tuned by improving the control strategy. In the final steady state operation, $\mathrm{PV}$ is providing power to the load as well as charging the battery. The diesel generator continues to operate, albeit at a reduced power point.

\section{Scenario 2}

This case shows the load being powered by the diesel generator and PV at the same time. The PV is supplying the majority of the load and is also charging the battery at the same time. The case then shows cloud coverage by reducing the irradiation from $100 \%$ to $30 \%$ and back to $100 \%$. This is shown in Fig. 10. As before, the steady state the THD remains below $3 \%$. Since there is no battery switching as in scenario 1 , there is no spike to $10 \%$. During the cloud coverage the PV output drops to nearly zero, while the diesel generator quickly ramps up power. The reverse occurs when the cloud cover has gone, and the system settles back to the initial steady state operation. This is shown in Fig. 11.

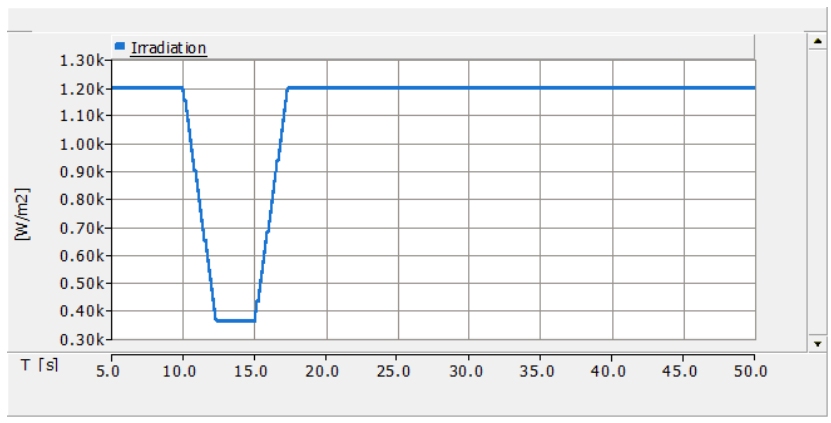

Fig. 10. Case 2, Irradiation.

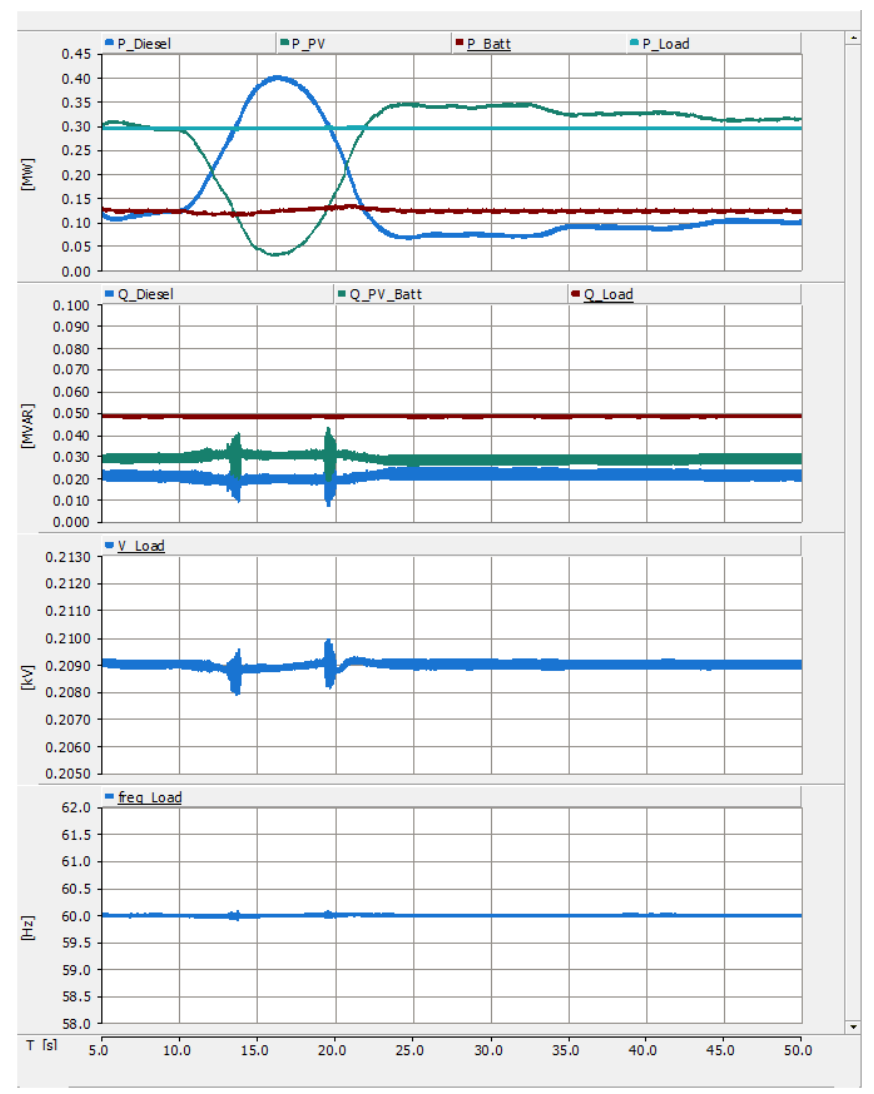

Fig. 11. Scenario 2, Real power $(\mathrm{P})$, reactive power $(\mathrm{Q})$, voltage $(\mathrm{V})$, and frequency (f) 
The following outlines various different tests that are important to consider for microgrids as discussed in this paper.

Testing DG connection: This stage demonstrates that the model works well when DG provides active power $(\mathrm{P})$ and reactive power $(\mathrm{Q})$ for the community load. In case of any fault in the system, the DGs are disconnected from the load and they reconnect after the fault clearance.

Testing battery system connection: This scenario tests and demonstrates when the battery system is providing full power to the community load in an off-grid mode. In this stage, the battery's voltage source converter (VSC) provides the voltage and frequency reference for the AC network.

Testing PV system connection: It's assumed that in this modeling, PV modules are always working with battery system due to the fact that high fluctuations in output power of PV modules could create serious power quality concerns. As such, this scenario illustrates the interconnection study of the PV system while it is producing maximum power. This will also investigate the effect of PV system interconnection on power quality and stability.

Test a fault condition on PV system, disconnect, connect and finally disconnect it: The aim in this scenario is to study what happens if an incident occurs in PV system while only battery and PV system are connected to the load. It is worth mentioning that if there is a fault in the battery system, both battery and PV system will be disconnected from the load since in this model, the PV system never works independently.
Testing Disconnection/Reconnection of the DG while Battery System is connected: This stage shows what happens when the DG suddenly disconnects in the presence of the battery. The algorithm is in such a way that if the DG is disconnected and the battery's SOC is critically low, disconnects the battery as well.

Testing Disconnection/Reconnection of the battery while DG is connected: Interconnection of the battery system while the DG is providing power for the community is critical. It is necessary to ensure that interconnection of the battery system will not affect the power reliability in the site.

Testing Connection/Disconnection/Reconnection of the PV system while DG and Battery system are connected: This will test the performance of the microgrid while all the components are working together. This also shows the system response when the PV is suddenly connected or disconnected to/from the grid.

Testing Connection of PV and Battery systems while DG is providing power: This scenario is for the moment when there is enough power from the PV system to supply the community load and charge the battery. It happens in most days during the spring, summer, and early fall.

\section{B. Performance Analysis}

A 24-hour performance graph is presented in Fig. 7. As seen both of the diesel generators operate at their optimal point which provides the maximum efficiently due to the storage system and the control algorithm.

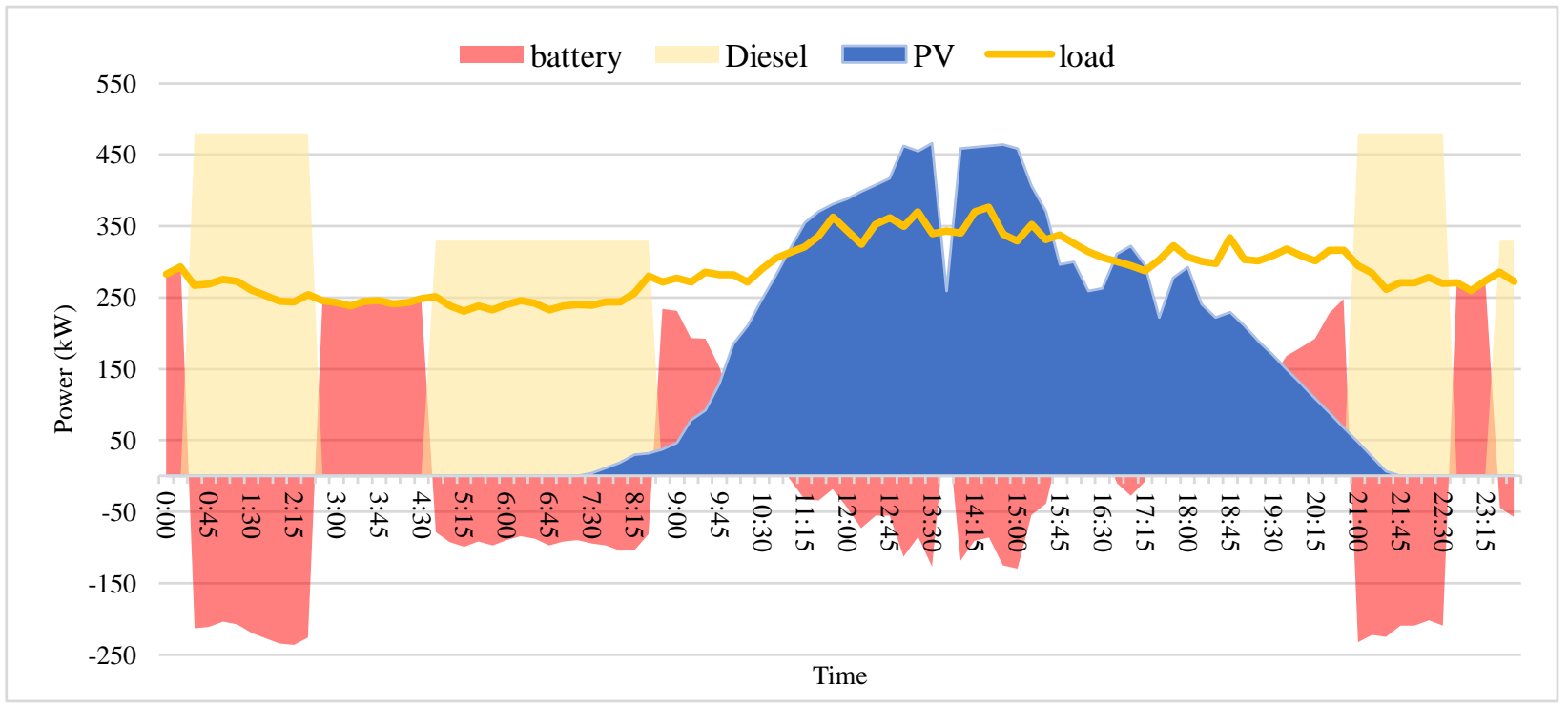

Figure 12- Performance analysis of the microgrid system in 24 hours

Testing DG and battery system interconnection: In this scenario, DG is running and providing power to the load. The battery system is being charged or discharged depending on its state of charge (SOC). If the SOC of the battery is lower than a certain pre-set amount, the diesel will be providing enough power for both the community load and batteries. In this case, the diesel runs on its optimal operating point which is about $90 \%$ of its nominal power. This happens during cloudy days in winter or during nights.
The storage system also supports the load when the clouds introduce a reduction in the generated power by PV round 14:00. This graph illustrates how the storage system plays a key role in the network to allow sudden changes in both the load consumption and power generation.

\section{CONCLUSION}

This paper presented the idea of the integration of renewable energy resources to the existing diesels generators in remote indigenous communities in Northern Canada, 
listing the benefits of such hybrid microgrids. First the challenges regarding taking action toward such change are outlined. Possible solutions are then provided. Barriers are not limited to technical aspects only.

In the ladder part of the paper a case study of a northern Manitoba was presented. In the simulation results performed in PSCAD/EMTDC, two scenarios illustrate how each component work cooperatively to reduce the annual diesel consumption. It is hoped of such a hybrid solution to reduce the risk and maintain the reliability of the grid.

In this light, this paper suggested a multiphase rollout plan in which the first phase, the idea is only to reduce the GHG emission by a certain ratio, then adding more solar modules and battery storage will be a second phase.

With the support of government funding, Indigenous and Northern Affairs Canada (INAC), and proven turnkey hybrid microgrid solutions, this paper suggested that the transitioning to clean energy in remote areas are doable and this is the fastest and most viable solution to reduce the GHG emission in the next five years.

\section{REFERENCES}

[1] MaRS Cleantech, "Enabling a Clean Energy Future for Canada" Remote Communities Introduction Impacts of Diesel Consumption In Canada 's Remote Communities," Adv. Energy Cent., pp. 1-7, 2015.

[2] J. Knowles, "Power shift: Electricity for Canada's remote communities," Conf. Board Canada, pp. 1-65, 2016.

[3] TechnoCenter Eolien, "Stand-alone Microgrids : A Major Asset for the Electrification of Off-grid Sites," pp. 1-31, 2018.

[4] The government of Canada, "Indigenous and Northern Affairs Canada Budget 2017 Highlights - Indigenous and Northern Investments,' 2017.

[5] Government of Canada, "Des communautés conçues pour l'avenir, in Le budget 2017: Plan budgétaire, March," 2017.

[6] M. Arriaga, C. A. Canizares, and M. Kazerani, "Renewable energy alternatives for remote communities in Northern Ontario, Canada,' IEEE Trans. Sustain. Energy, vol. 4, no. 3, pp. 661-670, 2013.

[7] "Statistical Review of World Energy," 2018. [Online]. Available: https://www.bp.com/content/dam/bp/business-

sites/en/global/corporate/xlsx/energy-economics/statisticalreview/bp-stats-review-2018-all-data.xlsx.

[8] C. Kost et al., "Levelized Cost of Electricity - Renewable Energy Technologies," Fraunhofer Inst. Sol. Energy Syst. ISE, 2018.

[9] G. Timilsina, "The Economics of Renewable Energy," Sustain. Dev., pp. 642-656, 2017.

[10] M. Arriaga, C. A. Canizares, and M. Kazerani, "Northern lights: Access to electricity in Canada's northern and remote communities," IEEE Power Energy Mag., vol. 12, no. 4, pp. 50-59, 2014.

[11] K. H. Solangi, M. R. Islam, R. Saidur, N. A. Rahim, and H. Fayaz, “A review on global solar energy policy," Renew. Sustain. Energy Rev. vol. 15, no. 4, pp. 2149-2163, 2011.

[12] S. Pelland, D. Turcotte, G. Colgate, and A. Swingler, "Nemiah valley photovoltaic-diesel mini-grid: System performance and fuel saving based on one year of monitored data," IEEE Trans. Sustain. Energy, vol. 3, no. 1, pp. 167-175, 2012 .

[13] F. Katiraei and C. Abbey, "Diesel plant sizing and performance analysis of a remote wind-diesel microgrid," 2007 IEEE Power Eng. Soc. Gen. Meet. PES, pp. 1-8, 2007.

[14] D. E. Olivares, C. A. Cañizares, and M. Kazerani, "A centralized optimal energy management system for microgrids," IEEE Power Energy Soc. Gen. Meet., pp. 1-6, 2011.

[15] R. Hunter and G. Elliot, Wind-diesel systems: a guide to the technology and its implementation. Cambridge University Press, 1994.

[16] C. T. Jones, Diesel Plant Operations Handbook. McGraw-Hill, 1991.

[17] P. Lundsager, "Overview of Diesel Issues in Wind-Diesel," in Proceedings of I nternational Wind-Diesel Workshop, 2011.

[18] Government of Canada, "Status of Remote/Off-Grid Communities in Canada," 2011.

[19] National Resources Canada, "The RETScreen Clean Energy Project Analysis software- Canmet ENERGY." [Online]. Available: http://www.retscreen.net/ang/centre.php.
[20] A. H. Mirzahosseini and T. Taheri, "Environmental, technical and financial feasibility study of solar power plants by RETScreen, according to the targeting of energy subsidies in Iran," Renew. Sustain Energy Rev., vol. 16, no. 5, pp. 2806-2811, 2012.

[21] R. Kaluthanthrige, A. D. Rajapakse, C. Lamothe, and F. Mosallat, "Optimal Sizing and Performance Evaluation of a Hybrid Renewable Energy System for an Off-Grid Power System in Northern Canada,' Technol. Econ. Smart Grids Sustain. Energy, vol. 4, no. 1, pp. 24-26, 2019.

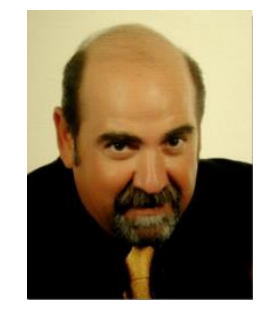

Tim J. Yusishen is the founder, President and CEO of Solar Solutions Canada Inc. now in its 34th year of design, manufacturing and distribution of renewable energy and conservation products globally. Solar Solutions has invented and commissioned some of the renewable energy industries first's and continue to lead the way as energy innovators to the engineering and architectural community in many parts of the world. Yusishen has worked 12 years prior in a multitude of industries form agriculture, shipbuilding aerospace, and nuclear engineering to managing a North American based distribution network. First trained as a young red seal Journeyman, Yusishen went on to study engineering at the Southern Alberta Institute of Technology and MIT. Yusishen also has founded Solar Engineers International fifteen years ago, focusing on consulting, design and engineering of renewable energy products and systems

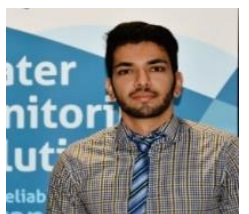

Amin Hajihosseinlu, P.Eng., M.Sc., received his $\mathrm{BSc}$ and MSc in Electrical Engineering from Shahid Beheshti University and university of Manitoba, respectively. He has been conducting research and development in the field of renewable energies, power conversion and electric vehicles since 2010

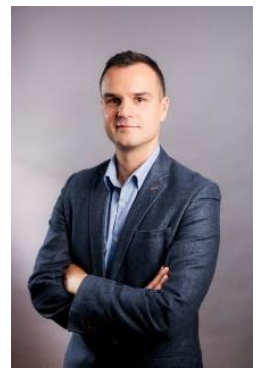

Mathias Pielahn, P.Eng., M.Sc., has been involved in a variety of PSCAD $^{\mathrm{TM}} / \mathrm{EMTDC}^{\mathrm{TM}}$ related projects, including EMT simulations studies for HVDC, wind/solar projects and SSCI studies. He has done extensive work on model development of various power system assets, most predominately relating to renewable energy technologies. Mathias has expert working knowledge of various software tools, including PSCAD, Matlab/Simulink, PSS/E and FORTRAN. Mathias received the B.Sc. degree from the University of Winnipeg (Honours - 2011) and the M.Sc. degree from the University of Manitoba (2014). In early 2018 he earned the professional engineer designation. In the same year he founded Pylon Technology Solutions Ltd., which explores current technology trends in various different fields. 


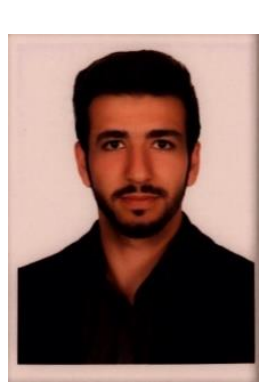

Iman Kaffashan was born in Shooshtar, Iran, in 1990. He received the B.Sc. degree from the Shahed University, Tehran, Iran, in 2012, and the M.Sc. degree from the K. N. Toosi University of Technology, Tehran, Iran, in 2014. He is currently pursuing the Ph.D. degree from the Electrical Engineering Department of the University of Manitoba, Winnipeg, Canada. His research activities include power system simulation, HVDC, flexible ac transmission, power converters, optimization, renewable energies, and uncertainty modeling

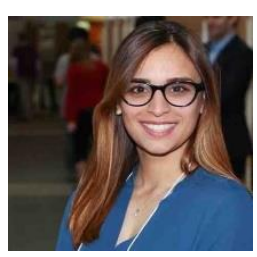

Azita Fazelkhah received her B.Sc. degree in electrical engineering from the Ferdowsi University of Mashhad, Iran, in 2010 and M. Sc. degree in biomedical engineering from the Amirkabir University of Technology, Tehran, Iran in 2013. She is currently working towards the Ph.D. degree at the Department of Electrical and Computer Engineering, University of Manitoba, Winnipeg, Canada. Her focus is on quantitative modeling of biological cells' dielectric properties.

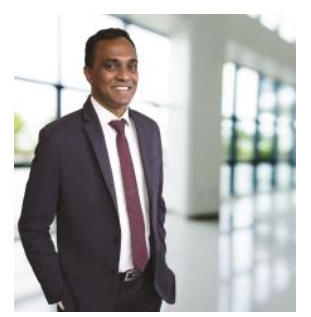

Dharshana Muthumuni, Ph.D., P.Eng., is the Managing Director of the Power Systems Technology Centre, a division of Manitoba Hydro International. He has over 20 years of experience in engineering studies using a variety of simulation products, including $\mathrm{PSCAD}^{\mathrm{TM}} / \mathrm{EMTDC}^{\mathrm{TM}}$ and PSS/E. His expertise is regularly sought out by clients around the world for his strong and wide ranging technical knowledge on power system behavior, model development, and simulation studies. He has lead the technical team to solve challenging problems, including HVDC and generation interconnections, wind integration into weak grids, FACTS-based solutions, SSR screening techniques, and power quality and harmonics. Dharshana has worked extensively and closely with equipment vendors to develop simulation models and techniques to address difficult interconnection problems. He has developed many custom models and simulations techniques for specific studies, including working closely with equipment vendors to address their simulation study requirements. In addition to his engineering study experience, Dharshana has been a key contributor to the development of the PSCAD simulation tool and has conducted training workshops on a variety of power system topics for our global clients. 